${ }^{1}$ 3-й Центральныц й военный клинический госпиталь

им. А.А. Вишневского

${ }^{2}$ Московский государственный университет пищевых производств ${ }^{3}$ ООО «ТНК СИЛМА»

${ }^{4}$ Первыцй Московский государственный

медицинский

университет им. И.М. Сеченова

\title{
Место полиметилсилоксана
}

\section{полигидрата в лечении \\ гастроэнтерологических заболеваний}

\author{
А.И. Павлов, д.м.н. ${ }^{1,2}$, А.В. Хованов, к.м.н. ${ }^{3}$, Ж.В. Фадина ${ }^{1}$, \\ А.К. Хаваншанов ${ }^{1}$, А.Б. Шамес, д.м.н. ${ }^{1}$, А.А. Павлова ${ }^{4}$
}

Адрес для переписки: Александр Игоревич Павлов, doctor-pavlov@mail.ru

Для цитирования: Павлов А.И., Хованов А.В., Фадина Ж.В. и др. Место полиметилсилоксана полигидрата в лечении гастроэнтерологических заболеваний // Эффективная фармакотерапия. 2020. Т. 16. № 1. С. 52-56.

DOI $10.33978 / 2307-3586-2020-16-1-52-56$

Исходя из собственного опыта, а также с учетом многолетних данных из открытых источников (PubMed, MedLine, e-library) проанализированы основные направления применения одного из современных энтеросорбентов полиметилсилоксана полигидрата в различных областях гастроэнтерологии. Определены перспективные направления для его дальнейшего использования.

Ключевые слова: энтеросорбенты, полиметилсилоксана полигидрат, заболевания желудочно-кишечного тракта

K ак известно, современные энтеросорбенты имеют преимущества перед классическими препаратами на основе глины и угля [1]. Одно из них - более длительное применение на всех этапах лечения, реабилитации и профилактики заболеваний желудочно-кишечного тракта (ЖКТ).

Современный кишечный адсорбент полиметилсилоксана полигидрат (ПМСПГ) прошел ряд клинических испытаний после широкого внедрения в клиническую практику. Результаты этих исследований позволяют адекватно оценить его эффективность и безопасность [2].
Согласно инструкции по медицинскому применению, ПМСПГ используется перорально. Многочисленные клинические данные свидетельствуют о применении ПМСПГ при заболеваниях всех отделов ЖКТ - от ротовой полости [3] до толстой кишки. Кроме того, адсорбент используют при болезнях гепатобилиарной системы и поджелудочной железы [4-7]. Терапевтический эффект препарата доказан как при органической патологии ЖКТ, так и при дисфункциях, связанных с патологическими процессами в других органах и системах, включая инфекционные процессы и ин- токсикацию различного генеза [8-12].

При болезнях пищевода, таких как рефлюкс-эзофагит, грыжа пищеводного отверстия диафрагмы, наблюдаются дисфагия и признаки локального воспаления. Использование адсорбентов в комплексном лечении способствует уменьшению воспалительного процесса и отека слизистой оболочки пищевода. При консервативном лечении энтеросорбенты оказывают противовоспалительное воздействие на престенотический участок пищевода у пациентов с послеожоговыми рубцовыми сужениями пищевода [13]. Уменьшение признаков воспаления и увеличение плотности структуры слизистой оболочки пищевода обусловлены уменьшением размеров интерстициальных пространств на фоне улучшения микроциркуляции и снижения отека слизистой оболочки, согласно морфометрическим данным.

Среди многочисленных болезней желудка следует выделить наиболее распространенные, требующие назначения современных энтеросорбентов. Речь идет о га- 
стродуодените, язвенной болезни и функциональных расстройствах. Энтеросорбенты эффективны в качестве адъювантной и альтернативной антибактериальной терапии при эрадикации Helicobacter pylori.

Следует отметить, что классические кишечные адсорбенты на основе угля и глины имеют противопоказания к применению при эрозивно-язвенных поражениях ЖКТ. Кроме того, при пероральном использовании соединений кремния не исключено его накопление в органах и тканях [14]. В то же время ПМСПГ не обладает такими побочными эффектами, что позволяет применять его при заболеваниях ЖКТ, в том числе сопровождающихся эрозивно-язвенными поражениями слизистой оболочки [15]. С внедрением новых энтеросорбентов появилась возможность ограничить использование антибактериальных препаратов. Это очень важно, поскольку антибиотикорезистентность представляет глобальную проблему. Подтверждение тому - политическая декларация заседания высокого уровня Генеральной Ассамблеи по проблеме устойчивости к противомикробным препаратам, принятая резолюцией Генеральной Ассамблеи ООН A/RES/71/3 от 5 октября 2016 г. Основой для решения проблемы устойчивости к противомикробным препаратам является принятый Всемирной организацией здравоохранения глобальный план действий по борьбе с устойчивостью к противомикробным препаратам.

В ряде исследований ПМСПГ использовали в качестве адъювантной терапии для эрадикации H. pylori у взрослых [16-19] и детей $[20,21]$. В рандомизированном исследовании ПМСПГ применяли в качестве альтернативного метода (монотерапия) для эрадикации H. pylori [22].

В одноцентровом открытом проспективном контролируемом пострегистрационном исследовании с участием 30 пациентов c H. pylori-ассоциированным га- стродуоденитом изучали эффективность и безопасность препарата Энтеросгель [22]. Динамику выраженности гастроинтестинальных жалоб оценивали с помощью стандартизированного опросника GSRS, предназначенного для определения качества жизни пациентов с заболеваниями ЖКТ. В начале и конце исследования всем больным проводили фиброгастродуоденоскопию и уреазный тест.

На фоне приема препарата Энтеросгель уменьшались такие симптомы, как изжога, отрыжка и избыточное отхождение газов. Достоверное улучшение эндоскопической картины слизистой оболочки желудка наблюдалось как после стандартной эрадикационной терапии, так и после лечения препаратом Энтеросгель: имела место тенденция к уменьшению признаков воспаления верхних отделов ЖКТ.

После курса монотерапии препаратом Энтеросгель инфицированность $H$. pylori снизилась с 86 до 47\%, что, по мнению авторов, указывало на антихеликобактерную активность препарата Энтеросгель. Таким образом, для усиления эффективности и безопасности традиционных эрадикационных схем авторы рекомендуют использовать Энтеросгель 22,5 г три раза в сутки в течение трех последовательных недель [22].

В работе Н.Д. Герасименко представлены отдаленные результаты терапии H. pylori в зависимости от соблюдения пациентами медицинских рекомендаций [19]. Изучено клиническое течение и проанализированы результаты обследования и лечения 139 пациентов с пепсической язвой, инфекцией H. pylori и повышенным содержанием фтора в крови и моче. В двух случаях также имела место пептическая язва желудка и двенадцатиперстной кишки. Показано, что назначение антиоксидантов и энтеросорбентов в дополнение к стандартной эрадикационной терапии способствует более полной эрадикации H. pylori, благоприятно- му течению пепсической язвы и улучшению состояния слизистой оболочки желудка.

В исследовании схем эрадикации H. pylori участвовали 159 детей в возрасте от семи до 16 лет c H. pylori-aссоциированным хроническим гастродуоденитом [20]. Все пациенты проживали на территориях крупных населенных пунктов с развитой сетью многопрофильных промышленных предприятий. Для эрадикации использовали производное 5-нитрофурана - нифуроксазид, для элиминации - ПМСПГ.

Проанализировав различные схемы эрадикации H. pylori у детей, исследователи пришли к выводу, что на территориях крупных населенных пунктов с развитой сетью многопрофильных промышленных предприятий эрадикационную терапию целесообразно проводить на фоне приема энтеросорбента ПМСПГ [20].

В другом контролируемом моноцентровом рандомизированном проспективном открытом сравнительном исследовании участвовало 55 детей в возрасте от семи до 18 лет с H. pylori-позитивной язвенной болезнью двенадцатиперстной кишки и колонизацией Candida. Во всех случаях отмечались рецидивирующее течение заболевания, устойчивость к стандартной терапии. В основной группе (30 детей), где к стандартной терапии добавляли ПМСПГ в течение 14 дней в возрастной дозе, общий терапевтический эффект составил $87 \%$ (в группе сравнения $-72 \% ; \mathrm{p}<0,05)$. При этом в основной группе наблюдались более легкое течение обострения заболевания, сокращение его продолжительности на $28 \%$ (пять дней) с полной эндоскопической ремиссией на фоне отрицательных результатов культурального микологического исследования биоптатов слизистой оболочки двенадцатиперстной кишки и снижения уровня циркулирующих кандидозных антител до следовых количеств [21].

Таким образом, результаты исследования подтвердили клиническую эффективность и без- 
опасность ПМСПГ в различных схемах лечения заболеваний желудка и двенадцатиперстной кишки, в том числе $H$. pylori-acсоциированных и сопровождающихся развитием эрозивно-язвенных дефектов.

Следует отметить, что при ряде чрезвычайно распространенных заболеваний кишечника фармакологические опции крайне ограниченны. К таким заболеваниям относятся синдром раздраженного кишечника (СРК) и диарея неинфекционного генеза [23]. Болезни кишечника обычно сопровождаются эндотоксикозом, дисбактериозом и нарушением пищеварения, приводящим к боли, диарее или запору, метеоризму, связанным непосредственно с ЖКТ, а также системными проявлениями (поражения кожи, мышц, сердца и сосудов, легких, почек, нервной и эндокринной систем).

К преимуществам ПМСПГ можно отнести относительно низкий мембранотропный эффект: по сравнению с мелкодисперсными сорбентами на основе неорганического кремния повреждающее воздействие ПМСПГ на нормальную флору значительно меньше [24]. При этом ПМСПГ способен ингибировать продукцию стафилококковых энтеротоксинов и удалять их из биологических субстратов [25].

Изучив возможности ПМСПГ адсорбировать из буферных растворов in vitro ряд веществ (основных желчных кислот, составляющих желчь), исследователи констатировали, что избыточная концентрация желчных кислот в толстой кишке часто становится причиной хронической диареи. При этом, например, в Великобритании 30\% пациентов с СРК, сопровождающимся диареей и связанным с мальабсорбцией желчных кислот, принимают секвестранты желчных кислот. Несмотря на то что Энтеросгель показал только умеренную или низкую адсорбцию четырех основных желчных кислот, этот эффект в сочетании с адсорбцией других эндогенных и экзогенных токсинов может иметь терапевтическое преимущество для пациентов с СРК с диареей (СРК-Д) [26].

В ряде работ показана роль ПМСПГ в восстановлении слизистой оболочки и лечении дисбактериоза 1-2-й степени [27-29]. В исследованиях принимали участие пациенты с различными проявлениями дисбактериоза (метеоризм, запор, диарея и их чередование, периодическая боль в животе). При микробиологическом исследовании фекалий выявлены увеличение количества гемолизирующей Escherichia coli и кокковой флоры, дисбаланс между нормальными видами микрофлоры кишечника, Klebsiella pneumoniae, Staphylococcus aureus, Proteus vulgaris. Больным проводилось традиционное лечение (диета, витаминотерапия, микробные препараты в зависимости от результатов анализов) в комплексе с ПМСПГ. В результате лечения с использованием Энтеросгеля в 98\% случаев отмечались субъективное улучшение и купирование клинической симптоматики уже на четвертый-пятый день терапии. После курса лечения при микробиологическом обследовании у всех больных отмечалась нормализация микробиоценоза кишечника.

У пациентов с язвенным колитом изучали показатели эндогенной интоксикации, а также влияние на эти показатели детоксикационной терапии (энтеросорбции). Исследования проводились в период обострения болезни с определением показателей до и после лечения. Экспериментальную группу составили больные, которым наряду с базисной терапией в качестве детоксиканта назначали ПМСПГ по стандартной схеме 14 дней. В контрольную группу вошли пациенты, получавшие только традиционное лечение. У всех больных изучена токсинсвязывающая способность альбуминов и глобулинов [12].

В начале лечения отмечалось снижение токсинсвязывающей способности альбумина сыворотки крови на $35,7 \%(\mathrm{p}<0,05)$ относительно показателей здо- ровых лиц и уменьшение содержания глобулинов, участвующих в процессах связывания токсинов, в 2,2 раза $(\mathrm{p}<0,05)$, что свидетельствовало о высокой эффективности ПМСПГ.

Актуальными и во многом нерешенными остаются вопросы фармакологической помощи при СРК-Д. В ряде исследований современные энтеросорбенты, в том числе в комбинации с прои пребиотиками, продемонстрировали хороший потенциал [6, 30-32]. В одном из исследований 30 пациентов с СРК-Д были разделены на две группы. В течение 21 дня пациенты основной группы получали ПМСПГ, пациенты контрольной группы - висмута трикалия дицитрат по одной таблетке четыре раза в день [31].

По данным опросника GSRS, в основной группе после проведенного лечения достигнуто статистически значимое снижение выраженности жалоб по шкалам абдоминальной боли, диарейного и диспепсического синдромов, а также по шкале суммарного измерения. В контрольной группе после терапии препаратом-компаратором статистически значимо снизилась интенсивность жалоб по шкалам абдоминальной боли, рефлюкс-синдрома, диарейного синдрома, диспепсического синдрома. Наиболее клинически значимыми изменениями у пациентов основной группы были нормализация частоты (урежение до семи раз в неделю) и формы стула (до четвертого типа по Бристольской шкале кала), уменьшение выраженности болевого синдрома [31].

В наших исследованиях принимали участие пациенты с неинфекционной диареей [32]. Все больные получали терапию в отношении основного заболевания, согласно рекомендациям Российской гастроэнтерологической ассоциации для соответствующей нозологии. Пациенты случайным образом были разделены на три группы. Пациенты первой группы в составе комплексной терапии получали ПМСПГ, пациенты второй - диоктаэдрический 
смектит. Пациентам третьей группы сорбенты не назначали. На фоне лечения с применением ПМСПГ удалось в более короткий срок добиться урежения стула независимо от генеза диареи (антибиотик-ассоциированная диарея, хронический панкреатит, СРК-Д) [32].

Классическая терапия острого панкреатита предполагает известные "холод, голод и покой», а также дезинтоксикацию, назначение ингибиторов протеаз, ферментов, ингибитора протонной помпы, спазмолитиков. Кроме того, существуют методики, снижающие проявления эндотоксикоза и дисбиоза - непременных спутников панкреатита.

В исследованиях проверялось положение о том, что в развитии хронического панкреатита не последнюю роль играет эндоток- сикоз, вызванный дисфункцией антиэндотоксиновой реактивности организма. Показано, что применение препарата Энтеросгель в комплексном лечении хронического панкреатита приводит к улучшению состояния мукозального антиэндотоксинового иммунитета (у 93,8\% больных в последующие три месяца после окончания лечения отсутствовали обострения) [33].

\section{- : "}

Итак, анализ литературных источников и результаты собственных исследований подтверждают целесообразность применения современных энтеросорбентов, в частности полиметилсилоксана полигидрата, в комплексном лечении пациентов с заболеваниями ЖКТ. Энтеросорбенты способствуют более полному и ускоренному выздоровлению за счет нормализации кишечного микробиоценоза, подавления перекисного окисления липидов, детоксикации организма вследствие выведения веществ средней молекулярной массы и активизации функций печени, раннему и щадящему заживлению язвенных образований, ранней эрадикации H. pylori, снижению токсической нагрузки на системы естественной детоксикации. В отличие от адсорбентов на основе угля и глины ПМСПГ показан при эрозивно-язвенных процессах в ЖКТ.

Указанные свойства ПМСПГ позволяют рекомендовать его к применению в качестве профилактического и поддерживающего средства, а также в составе комплексной терапии различных заболеваний ЖКТ.

\section{Литература}

1. Павлов А.И., Хованов А.В., Фадина Ж.В. Борьба с эндогенной интоксикацией и восстановление кишечного барьера как цели назначения Энтеросгеля при диарее неинфекционного генеза // Эффективная фармакотерапия. 2019. № 2. С. 54-62.

2. Martin K., Bégaud B., Latry P. et al. Differences between clinical trials and postmarketing use // Br. J. Clin. Pharmacol. 2004. Vol. 57. № 1. P. 86-92.

3. Daminova N.R., Kamilov Kh.P., Sadikov A.A. Experience of the optimum exposition of Enterosgel establishment for treatment of the periodontal disease at patients with vesicular disease // European Science Review. 2016. № 1. Р. 47-49.

4. Знаменский В.А., Возианов А.Ф., Возианова Ж.В. и др. Применение лечебно-профилактических препаратов, изготовленных на основе кремнийорганических сорбентов. Методические рекомендации. Киев, 1996.

5. Осадчая О.И., Шмакова Е.А., Боярская А.М. Метаболическая интоксикация и пути ее коррекции у больных с алкогольным поражением печени // Медицина неотложных состояний. 2009. № 6 (25). С. 65-66.

6. Павлов А.И., Хованов А.В., Хаваншанов А.К. и др. Современная энтеросорбция в коррекции уровня эндотоксинов при неинфекционной диарее // Эффективная фармакотерапия. 2019. Т. 15. № 28. С. 32-38.

7. Павлов А.И., Хованов А.В., Хаваншанов А.К. и др. Место современной энтеросорбции в лечении и профилактике алкогольной болезни печени (обзор литературы) // Эффективная фармакотерапия. 2019. Т. 15. № 18. C. 36-41.

8. Горчакова Н.О., Чекман І.С., Бабак В.В. и др. Вивчення фармакологічної активності та безпечності препа- рату «Ентеросгель» // Мистецтво лікування. 2005. № 6. C. 76-77.

9. Беляева О.А., Семенов В.Г. Применение энтеросорбции в комплексной терапии заболеваний печени // Аптека. 2003. № 30. С. 7.

10. Мороз Л.В., Палій І.Г. Вивчення впливу детоксиканту Ентеросгель на клінічні та лабораторні показники при хронічних вірусних гепатитах // Мистецтво лікування. 2005. № 5. С. 94-95.

11. Гебеш В.В., Семенченко И.Г. Применение Энтеросгеля при лечении больных с механической желтухой // Клиническое применение препарата Энтеросгель у больных с патологией органов пищеварения. M., 2000. C. 66-68.

12. Осадчая О.И., Боярская А.М. Клиническая эффективность применения энтеросорбции для купирования синдрома эндогенной интоксикации у больных с неспецифическим язвенным колитом // Лекарства Украины. 2009. № 6 (132).

13. Чикинев Ю.В., Антонов А.Р., Коробейников А.В. Эффективность сорбционной терапии у больных рубцовыми сужениями пищевода // Патологическая физиология и экспериментальная терапия. 2006. № 3. C. 21-22.

14. Scholey D.V., Belton D.J., Burton E.J., Perry C.C. Bioavailability of a novel form of silicon supplement // Sci. Rep. 2018. Vol. 8. № 1. P. 17022.

15. Мамонов Д.А., Зотин М.С., Шмушкович Т.Б. Энтеросорбция в хирургическом лечении язвенных гастродуоденальных кровотечений. Материалы V Российского симпозиума «Хирургия 2004». М., 2004. С. 118-119.

16. Каменская О.В. Морфофункциональные особенности собственной пластинки слизистой желудка при различных способах лечения язвенной болезни 
желудка: автореф. дисс. ... канд. мед. наук. Новосибирск, 2002.

17. Чеботарев А.Н. Оптимизация проведения антихеликобактерной терапии у больных язвенной болезнью желудка и двенадцатиперстной кишки, осложненной гастроинтестинальным кровотечением: автореф. дисс. ... канд. мед. наук. М., 2004.

18. Ткач С.М. Эффективность энтеросорбента Энтеросгель в комплексной антихеликобактерной терапии пептических язв // Consilium medicum Ukraine. 2011. T. 5. № 4. C. 12-13.

19. Герасименко Н.Д. Эффективность амбулаторной терапии язвенной болезни с учетом коррекции антиоксидантного и иммунного статусов в условиях избытка фторидов в окружающей среде: автореф. дисс. ... канд. мед. наук. Симферополь, 2004.

20. Зайцева Н.В., Аминова А.И., Акатова А.А., Минченко Е.Ю. Особенности эрадикационной терапии хронического гастродуоденита, ассоциированного с H. pylori у детей, проживающих в экологически неблагоприятных условиях // Российский вестник перинатологии и педиатрии. 2009. T. 54. № 4. С. 49-53.

21. Маланичева Т.Г., Зиатдинова Н.В. Энтеросорбция в лечении язвенной болезни двенадцатиперстной кишки у детей в условиях инфицирования Helicobacter pylori и колонизации Candida // Главный врач Юга России. 2018. № 2 (60). С. 49-52.

22. Tkachenko E.I., Avalueva E.B., Skazyvaeva E.V. et al. Efficiency and safety of siliceous enterosorbents in the therapy of Helicobacter pylori-associated diseases of the upper gastrointestinal tract // Minerva Gastroenterol. Dietol. 2016. Vol. 62. Suppl. 1. № 3.

23. Гастроэнтерология. Национальное руководство / под ред. В.Т. Ивашкина, Т.Л. Лапиной. М.: ГЭОТАРМедиа, 2018.

24. Ніцак О.В. Визначення сорбційної активності кремнійорганічних ентеросорбентів по відношенню до мікроорганізмів // Вісник проблем біології і медицини. 2008. № 3. С. 89-93.

25. Флуер Ф.С., Кудрявиева А.В., Титарев С.И., Бъкова И.Б. Средство для ингибирования продукции стафилококковых энтеротоксинов и удаления их из биологических субстратов // Журнал микробиологии, эпидемиологии и иммунобиологии. 2017. № 3. C. 71-77.

26. Howell C.A., Mikhalovsky S.V., Markaryan E.N., Khovanov A.V. Investigation of the adsorption capacity of the enterosorbent Enterosgel for a range of bacterial toxins, bile acids and pharmaceutical drugs // Sci. Rep. 2019. Vol. 9. № 1. P. 5629.

27. Льсиков Ю.А., Петухов А.Б., Смирнов К.А. Влияние энтеросорбента Энтеросгель на состояние слизистой оболочки желудка и тонкой кишки // Российский журнал гастроэнтерологии, гепатологии, колопроктологии. 2000.

28. Мороз Л.В., Палій І.Г., Ткаченко Т.В. Застосування препарату Ентеросгель у комплексній терапії хворих на гострі вірусні гепатити із супутнім дисбактеріозом кишківника // Нова медицина. 2005. № 1. C. $72-74$.

29. Чернобровый В.Н., Палий И.Г. Применение препарата Энтеросгель для лечения дисбактериоза кишечника // Мистецтво лікування. 2003. № 5. С. 74.

30. Фадеенко Г.Д., Чирва О.В., Горб Ю.Г. Использование пребиотиков в лечении синдрома раздраженного кишечника // Сучасна гастроентерологія. 2013. № 4 (72). C. 52-59.

31. Tkachenko E.I., Avalueva E.B., Skazyvaeva E.V. et al. Efficiency and safety of Enterosgel (polymethylsiloxane polyhydrate) in the treatment of irritable bowel syndrome // Minerva Gastroenterol. Dietol. 2015. Vol. 61. Suppl. 1. № 2 .

32. Яковлев А.А., Писковеи В.А. Структура психосоматических нарушений у больных с синдромом раздраженного кишечника и оценка эффективности дифференцированной терапии. Казань: Практика, 2009. C. $43-47$.

33. Нахашова B.E. Дисбаланс системного и мукозального антиэндотоксинового иммунитета у больных хроническим панкреатитом // Украинский медицинский альманах. 2008. Т. 11. № 5. C. $109-113$.

\section{Place of Polymethylsiloxane Polyhydrate in the Treatment of Gastroenterological Diseases}

A.I. Pavlov, MD, $\mathrm{PhD}^{1,2}$, A.V. Khovanov, $\mathrm{PhD}^{3}$, Zh.V. Fadina ${ }^{1}$, A.K. Khavanshanov', A.B. Shames, $\mathrm{MD}, \mathrm{PhD}^{1}$, A.A. Pavlova ${ }^{4}$

${ }^{1}$ A.A. Vishnevsky $3^{\text {rd }}$ Central Military Clinical Hospital

${ }^{2}$ Moscow State University of Food Production

${ }^{3}$ TNK SILMA, LLC

${ }^{4}$ I.M. Sechenov First Moscow State Medical University

Contact person: Aleksandr I. Pavlov, doctor-pavlov@mail.ru

Based on own experience, as well as taking into account long-term data from open sources (PubMed, MedLine, e-library), there were analyzed the main directions of application of one of the modern enterosorbents of polymethylsiloxane polyhydrate in different fields of gastroenterology. Identified prospective directions for its further use.

Key words: enterosorbents, polymethylsiloxane polyhydrate, diseases of the gastrointestinal tract 